\title{
Naringin ameliorates memory deficits and exerts neuroprotective effects in a mouse model of Alzheimer's disease by regulating multiple metabolic pathways
}

\author{
XIANGDONG MENG $^{1 *}$, MINGMING FU $^{2 *}$, SHOUFENG WANG ${ }^{3}$, \\ WEIDA CHEN $^{3}$, JIANJIE WANG ${ }^{4}$ and NING ZHANG ${ }^{5}$ \\ ${ }^{1}$ Nanchong Central Hospital, Second Clinical Medical College; ${ }^{2}$ Foreign Language Department, \\ North Sichuan Medical College (University), Nanchong, Sichuan 637000; ${ }^{3}$ Affiliated First Hospital, \\ Jiamusi University; ${ }^{4}$ College of Basic Medicine, Jiamusi University, Jiamusi, Heilongjiang 154002; \\ 5 Jiamusi College, College of Pharmacy, Heilongjiang University of Chinese Medicine, \\ Jiamusi, Heilongjiang 154007, P.R. China
}

Received August 18, 2020; Accepted February 1, 2021

DOI: $10.3892 / \mathrm{mmr} .2021 .11971$

\begin{abstract}
The aim of the present study was to investigate the neuroprotective effects of naringin on the memory impairment of hydrocortisone mice, and to elucidate the potential underlying molecular mechanisms. In the present study, a hydrocortisone model was constructed. Novel object recognition, Morris water maze and step-down tests were performed in order to assess the learning and memory abilities of mice. Hematoxylin and eosin staining was used to observe pathological changes in the hippocampus and hypothalamus. Transmission electron microscopy was used to observe the ultrastructural changes in the hippocampus. Immunohistochemistry was used to detect the expression of ER $\alpha$ and ER $\beta$. Western blotting was performed to detect the expression of each protein in the relevant system. It was found that naringin can significantly improve cognitive, learning and memory dysfunction in mice with hydrocortisone memory impairment. In addition, naringin can exert neuroprotective effects through a variety of mechanisms, including amyloid $\beta$ metabolism, Tau protein hyperphosphorylation, acetylcholinergic system, glutamate receptor system, oxidative stress and cell apoptosis. Naringin
\end{abstract}

Correspondence to: Dr Jianjie Wang, College of Basic Medicine, Jiamusi University, 258 University Street, Jiamusi, Heilongjiang 154002, P.R. China

E-mail: jxdx1122@163.com

Dr Ning Zhang, Jiamusi College, College of Pharmacy, Heilongjiang University of Chinese Medicine, 53 Guanghua Street, Jiamusi, Heilongjiang 154007, P.R. China

E-mail: zhangning0454@163.com

*Contributed equally

Key words: Alzheimer's disease, memory impairment, naringin, amyloid- $\beta$, apoptosis can also affect the expression of phosphorylated-P38/P38, indicating that the neuroprotective effect of naringin may also involve the MAPK/P38 pathway. The results of the present study concluded that naringin can effectively improve the cognitive abilities of mice with memory impairment and exert neuroprotective effects. Thus, naringin may be a promising target drug candidate for the treatment of Alzheimer's disease.

\section{Introduction}

Alzheimer's disease (AD), the most common neurodegenerative disease, is clinically characterized by progressive memory impairment and cognitive dysfunction (1). Pathologically, the disease is characterized by the presence of extracellular plaques of amyloid- $\beta(A \beta)$, intracellular tangles of hyperphosphorylated tau protein (2) and loss of forebrain cholinergic neurons (3). As reported, the average course of disease from AD to death is $\sim 10$ years. In addition, early symptoms of the disease are not obvious, and the majority of patients with AD do not know when they develop the disease. Therefore, as time passes, the condition of patients with $\mathrm{AD}$ becomes more serious, eventually leading to the complete loss of learning, cognition and language abilities (4).

There are numerous factors that contribute to the development of $\mathrm{AD}$, and various pathogenesis mechanisms have been reported. In the $A \beta$ theory, $A \beta$-protein is considered to be the central link to the incidence of AD. A previous study has shown that the concentration of $A \beta$ in the brain tissue of patients with early AD is significantly higher compared with that in the healthy population, which has a toxic effect on brain neurons and leads to the loss or death of neurons (5). In the Tau protein abnormal modification theory, abnormal modification of Tau protein can cause the Tau protein to lose the compositional function of tubulin, triggering the disintegration of microtubules, thereby affecting the normal transport function of neuronal cells and nerve endings, and ultimately leading to neuron degeneration and synaptic degeneration (6). As presented in the cholinergic system damage theory, the 
central cholinergic system of patients with AD has obvious damage and defects, which are consistent with the clinical symptoms of patients with $\mathrm{AD}$ (7). Oxidative stress refers to the imbalance between the peroxide action and antioxidant mechanisms in the body, which leads to excessive production of oxygen-free radicals and peroxides, causing damage to cells (8). In the glutamate receptor theory, glutamate and its receptors play an important role in the function of the body's nervous system. Its receptors are involved in the growth and development of neurons, the performance of learning and memory capabilities and the maintenance of synaptic plasticity (9). Apoptosis of brain neuronal cells in patients with $\mathrm{AD}$ is the main cause of nerve damage, and it is also the final pathway of various theories on the pathogenesis of AD. Based on relevant literature studies, $A \beta$ aggregation, oxidative stress and mitochondrial dysfunction in patients with $\mathrm{AD}$ are all important causes of neuronal cell apoptosis (10). Due to the diversity and complexity of its mechanisms, there is not yet a cure or efficient form of treatment for AD. Therefore, the development of anti-AD drugs has become an important area of research.

Natural compounds and their derivatives have attracted increasing attention due to their inherent chemical diversity, and a number of them have become potential drug candidates (11). Drynaria rhizome, also known as Gu-Sui-Bu, is a common plant widely distributed throughout southern China (12). The roots of Drynaria rhizome were conventionally regarded as a medicine against osteoporosis and bone resorption, while recently it has increasingly been used to treat neurodegenerative diseases, such as AD (13). Naringin (Fig. 1), one of the main active substances extracted from Drynaria rhizome has attracted increased attention due to its extensive antioxidant, anti-inflammatory, anti-apoptotic, anti-ulcer, anti-osteoporosis and anticancer effects $(14,15)$. According to previous reports, naringin can attenuate the behavioral changes and cognitive impairment in the epilepsy model induced by haiendic acid (16) and the Huntington model induced by 3-nitropropionic acid (17). In addition, naringin treatment can decrease oxidative damage and reverse histopathological changes in the cortex, striatum and hippocampus caused by ischemia-reperfusion (18). Furthermore, previous experiments have shown that it can also improve the long-term memory of transgenic AD mice, and also play a neuroprotective role (19). However, to the best of our knowledge, there is currently little information available regarding the effects of naringin on long-term cognitive impairment in patients with $\mathrm{AD}$, and the mechanisms that may be involved are not yet fully understood.

The present study isolated naringin from Drynaria rhizome and studied the effects of naringin on cognitive impairment and neuropathology in an AD mouse model. The results of the present study suggested that naringin can improve the ability of learning and memory in $\mathrm{AD}$ model mice through a variety of ways, thus exerting neuroprotective effects.

\section{Materials and methods}

Groups and treatments. A total of 75 male mice (age, 8 weeks; weight, $25 \pm 5$ g), provided by Liaoning Changsheng Biotechnology Co., Ltd., were included in the present study
[SCXK (Liaoning) 2015-0001]. All animals were raised in an environment where the ambient temperature and relative humidity were $21 \pm 2^{\circ} \mathrm{C}$ and $60 \pm 10 \%$, respectively. The present study was approved by the ethics committee of Clinical Medical College of Jiamusi University (approval no. 201803). All procedures were in strict accordance with the recommendations in the Guide for the Care and Use of Laboratory Animals of the National Institutes of Health.

The mice were randomly divided into five groups: Sham group (distilled water), hydrocortisone model group (25 mg/kg/day; Chengdu Mansitebio-Technology Co, Ltd.), KN15112502 group $(585 \mathrm{mg} / \mathrm{kg} /$ day; Shijiazhuang No. 4, Pharmaceutical), naringin group (100 mg/kg/day) and naringin + estrogen receptor (ER) inhibitor group (ICI182780, $0.072 \mathrm{mg} / \mathrm{kg} / \mathrm{day}$; Tocris Bioscience). The Sham group was used as the control group to verify the success of the model construction. KN15112502 is Kang Nao Shuai Jiao Nang, which served as a positive control in the study to testify the effect of naringin on memory impairment mice. The naringin group is a single-drug group to verify its neuroprotective effect on mice with memory impairment. ICI182780 is an ER inhibitor that can block the binding to the receptor. By adding this inhibitor, it is determined whether naringin binds to ER and mediates the neuroprotective effect of associated pathways. The Sham group and the hydrocortisone model group were given intragastrically with distilled water; the KN15112502 group and the naringin group were gavaged with the corresponding drugs; the Naringin + ER inhibitor group was intraperitoneally injected with ER inhibitor, and naringin was given by gavage after $15 \mathrm{~min}$. After 3 weeks of continuous gavage, except for the control group, hydrocortisone was administered to the other four groups for modeling. After the model was established (20), the drug was continuously administered for 1 week, and then behavioral experiments were conducted on the mice in each group. The flowchart of animal experimental procedures is shown in Fig. 2.

New object recognition (NOR). Briefly, the procedure is divided into two phases: Training phase and testing phase. In the training phase, two identical objects were prepared at one end of the test box, and the mice were placed with their backs to the objects in the box and left to explore freely for $5 \mathrm{~min}$. After $1 \mathrm{~h}$ of training, any of the two objects in the test box was replaced with another completely different new object, and the other object remains unchanged. The mice were placed in the same place and allowed to explore freely for $5 \mathrm{~min}$. The recognition time of the new and old objects by the mice were represented by $\mathrm{Tn}$ and $\mathrm{Tf}$, respectively, and the recognition index was calculated as (TN-TF)/(Tn+Tf).

Morris water maze (MWM). During the 5 consecutive days of training, each rat was placed in water to search for the platform situated in the water. From the time the mice entered the water, the time it took them to locate the platform within $90 \mathrm{sec}$ was recorded, which was the escape latency. If the mice found the platform within $90 \mathrm{sec}$, they were allowed to stay on it for $30 \mathrm{sec}$. If the mice could not find the platform within $90 \mathrm{sec}$, they were artificially placed on the platform for $30 \mathrm{sec}$ to enhance their memory. At the 6th day, the platform was removed and the same water inlet point was selected. Within 


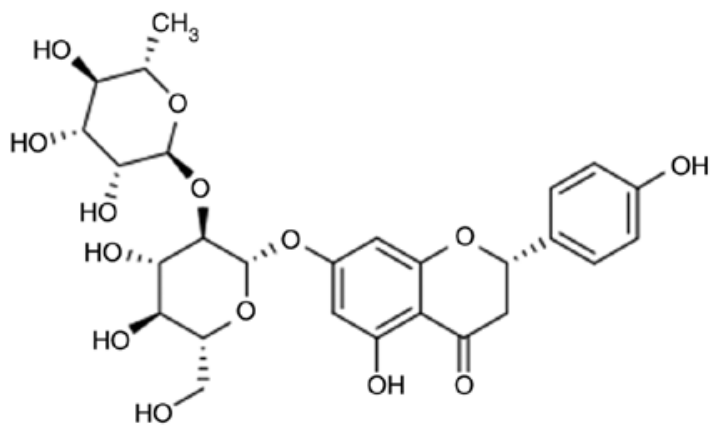

Figure 1. Structure of naringin.

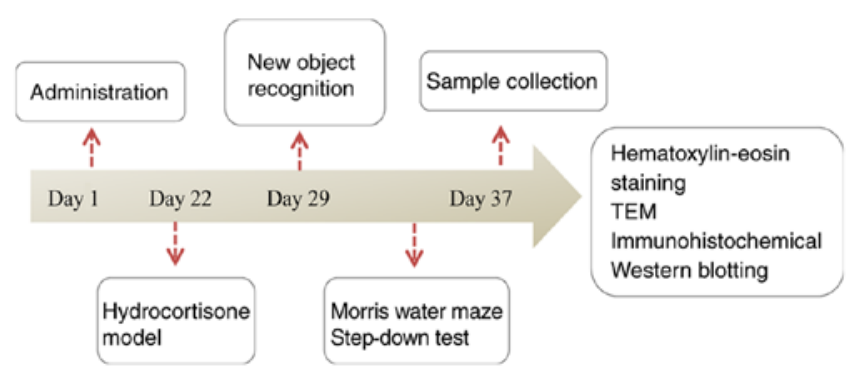

Figure 2. Flowchart of animal experimental procedures. TEM, transmission electron microscopy.

$90 \mathrm{sec}$, the traveled distance, time and number of crossing the original platform were recorded.

Step-down test. The mice were placed on the platform jumper for $3 \mathrm{~min}$. The copper gate was electrified and the mice were trained for $5 \mathrm{~min}$. During this period of time, the mice would experience the repeated process of jumping onto the platform after being shocked, from the platform to the copper grid, and then jumping back to the platform after being shocked. After $24 \mathrm{~h}$, the mice were tested and the method was consistent with the training. Briefly, the mice were first placed on the platform, and the number of jumps from the platform within 5 min was recorded as the number of errors. The incubation period was defined as the time the mouse first jumped off the platform.

Hematoxylin and eosin $(H \& E)$ staining. After the behavioral experiment, the mice were anesthetized (1\% pentobarbital sodium, $35 \mathrm{mg} / \mathrm{kg}$, intraperitoneal injection; Dainippon Sumitomo Pharma) and decapitated. The brain was quickly removed, and the hypothalamus and hippocampus were stripped. Briefly, the hippocampal and hypothalamic tissues were fixed in 10\% formalin (cat. no. 0-10-02; Beijing Yili Fine Chemicals Co., Ltd.) for $24 \mathrm{~h}$ at $37^{\circ} \mathrm{C}$. Subsequently, the fixed tissues were embedded in paraffin and cut into $5-\mu \mathrm{m}$ sections with a microtome. After regular dewaxing using 50\% xylene for $20 \mathrm{~min}$ and dehydration with $80 \%$ ethanol for $20 \mathrm{~min}$ at $37^{\circ} \mathrm{C}$, the sections were stained with hematoxylin for $5 \mathrm{~min}$ at $37^{\circ} \mathrm{C}$, and eosin for $4 \mathrm{~min}$ at $37^{\circ} \mathrm{C}$. Finally, histopathological changes in the hippocampus and hypothalamus were observed under a light microscope (magnification, x200).

Transmission electron microscopy (TEM). The hippocampus tissues $\left(1 \mathrm{~mm}^{3}\right)$ were fixed in $2.5 \%$ phosphate-buffered glutaraldehyde for $20 \mathrm{~min}$ at $37^{\circ} \mathrm{C}$ and post-fixed in $1 \%$ osmium tetroxide in water at $37^{\circ} \mathrm{C}$ for $30 \mathrm{~min}$. This was repeated three times, for 15 min each time. Following gradient dehydration for each time $15 \mathrm{~min}$ with ethanol and acetone (50\% ethanol; $70 \%$ ethanol; $90 \%$ ethanol; $90 \%$ acetone; $100 \%$ acetone) at $37^{\circ} \mathrm{C}$, the cells were embedded and sectioned. The samples were double stained with $50 \%$ uranyl acetate and lead citrate for $20 \mathrm{~min}$ at $37^{\circ} \mathrm{C}$, and the ultrastructure of the hippocampus tissues were observed with a JEM-1200EX TEM (magnification, x200; JEOL, Ltd.).

Immunohistochemical analysis. Briefly, endogenous peroxidase activity within the sections was quenched by incubating the sections with $3 \% \mathrm{H}_{2} \mathrm{O}_{2}$ for $15 \mathrm{~min}$ at $37^{\circ} \mathrm{C}$ after regular dewaxing and dehydration. According to the aforementioned method, the tissues were incubated in a humidified chamber with primary antibodies: $\operatorname{ER} \alpha(1: 1,000$; cat. no. 8644T; Cell Signaling Technology, Inc.), $\operatorname{ER} \beta$ (1:1,000; cat. no. k1437Hu22-KALANG; https://www.biomart.cn/infosupply/31407572.htm) overnight at $4^{\circ} \mathrm{C}$. On the following day, the tissues were washed with PBS and incubated with secondary antibody (1:1,000; cat. no. bs-0295G-H; BIOSS) for $1 \mathrm{~h}$ at $37^{\circ} \mathrm{C}$. For the negative controls, the primary antibodies were replaced with PBS. Stained sections were counterstained with $\mathrm{DAB}$ for $5 \mathrm{~min}$ at $37^{\circ} \mathrm{C}$ and observed using a light microscope (magnification, x200; Olympus Corporation).

Western blotting. According to the manufacturer's instructions, the proteins were extracted using RIPA lysate with proteinase inhibitor and phosphatase inhibitor (Roche Diagnostics) and the concentration was measured using a bicinchoninic acid assay. Protein samples (35 $\mu \mathrm{g})$ were then separated via SDS-PAGE gels (12\%) and transferred to a PVDF membrane (EMD Millipore). After blocking with 5\% non-fat dried milk for $2.5 \mathrm{~h}$ at $37^{\circ} \mathrm{C}$, the PVDF membrane was incubated with primary antibodies against: APP (1:1,000; cat. no. bs-12503R; BIOSS), BACE1 (1:1,000; cat. no. 5606T; Cell Signaling Technology, Inc.), CDK5 (1:1,000; cat. no. bs-10258Rm; BIOSS), p-Tau ${ }^{396}$ (1:1,000; cat. no. bs-3446R; BIOSS), glutamate receptor subunit 1 (NMDAR1) (1:1,000; cat. no. bs-23343R; BIOSS), glutamate receptor 2 (GluR2; 1:1,000; cat. no. bs-13385R; BIOSS), calcium/calmodulin-dependent protein kinase type II (CAMKII; 1:1,000; Boster), Bad (1:500; cat. no. A00183; Boster), caspase-3 (1:500; cat. no. bs-0081R; BIOSS), Bcl-2 (1:500; cat. no. bs-0032R; BIOSS), ER $\beta$ (1:1,000; cat. no. k1437Hu22; KALANG; https://www.biomart.cn/infosupply/31407572.htm), p-P38 $(1: 1,000$; cat. no. bs-2210R; BIOSS) and $\beta$-actin $(1: 1,000$; cat. no. bs-0061R; BIOSS) overnight. On the following day, the protein samples were incubated with the secondary antibody (1:1,000; cat. no. bs-0295G-H; BIOSS) at room temperature for $45 \mathrm{~min}$. The western blotting images were observed with ECL reagent (Beyotime Institute of Biotechnology), and the optical density of the target band was measured using a gel image processing system (Gel-Pro-Analyzer software).

Measurement of superoxide dismutase (SOD), malondialdehyde (MDA), nitric oxide $(N O)$, choline acetyl transferase (ChAT), acetylcholinesterase (AchE) and acetylcholine (Ach) levels. Concentrations of SOD, MDA, NO and Ach, and the 
A
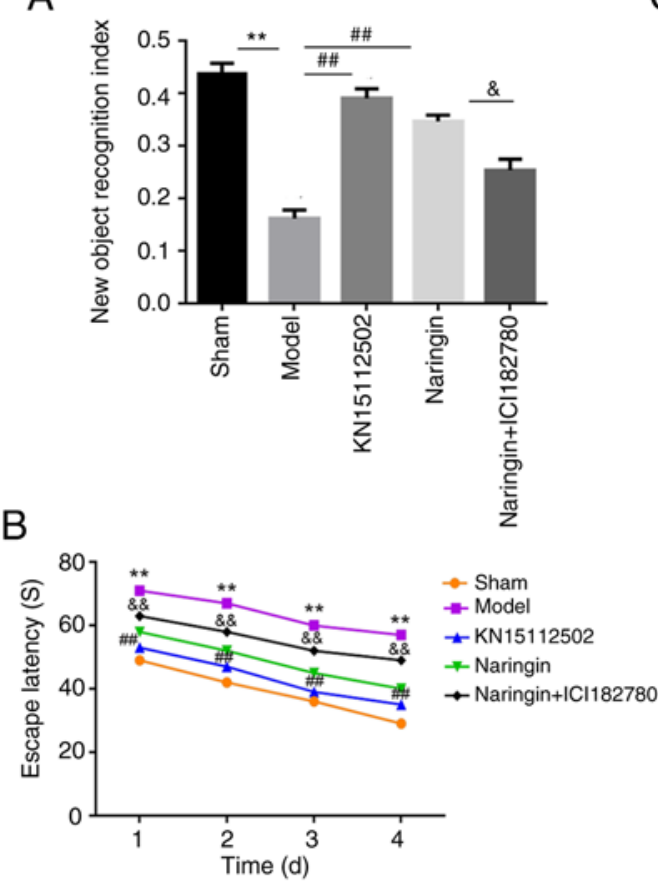

C
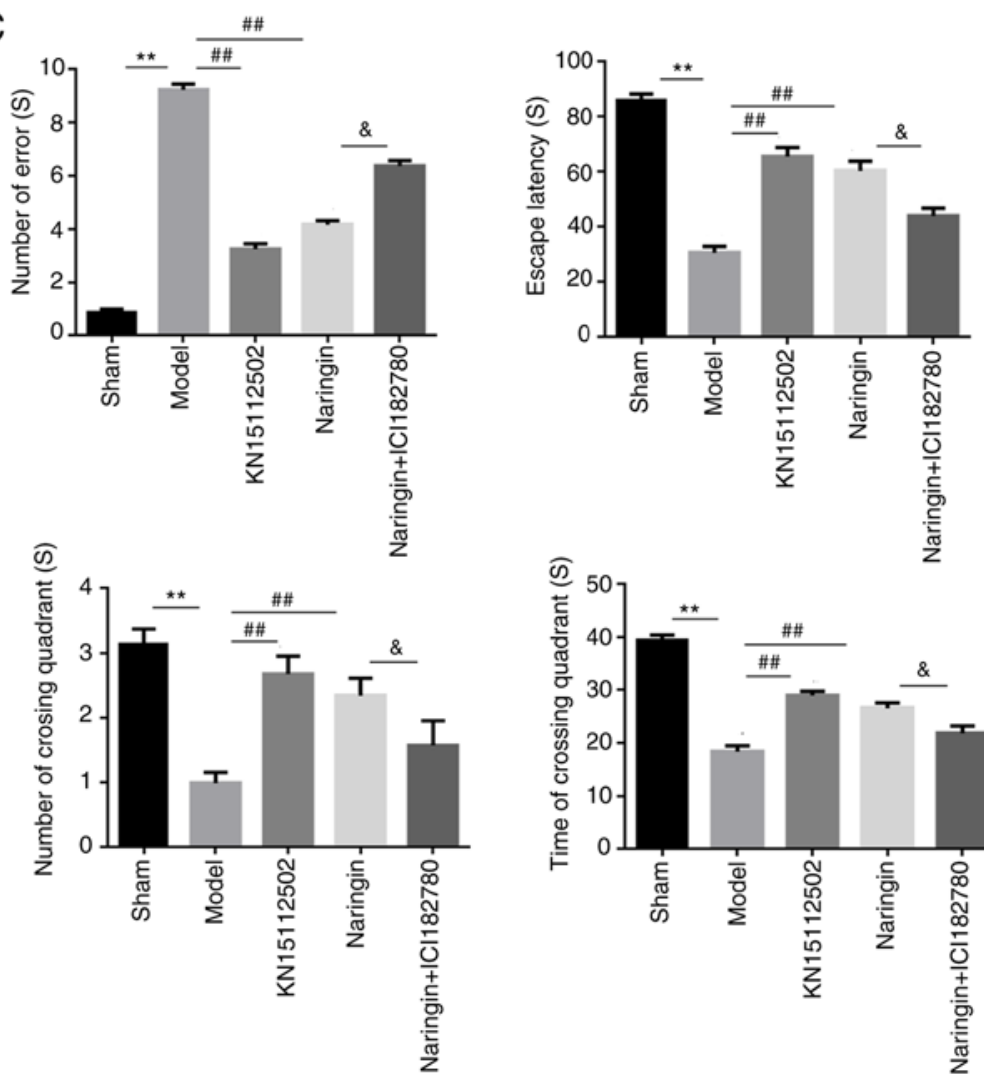

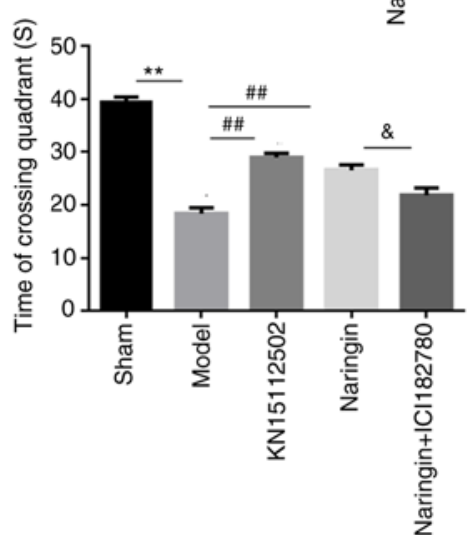

Figure 3. Naringin improved memory and cognition in mice with memory impairment. (A) The comparison of new object recognition index of each group. (B) Escape latencies, the number of mice crossing the quadrant of platform and the time of crossing target quadrant in the Morris water maze in each group. (C) Number of errors and the escape latencies in the step-down test of each group. ${ }^{* *} \mathrm{P}<0.01$ vs. sham group; ${ }^{\# \#} \mathrm{P}<0.01$ vs. model group; ${ }^{\star} \mathrm{P}<0.05$, ${ }^{\& \&} \mathrm{P}<0.01$ vs. naringin group.

activity of ChAT and AchE in the tissues were assessed using a commercially available SOD kit (Nanjing Jiancheng Bioengineering Institute), MDA kit (Nanjing Jiancheng Bioengineering Institute), NO kit (Nanjing Jiancheng Bioengineering Institute), Ach kit (Nanjing Jiancheng Bioengineering Institute), ChAT kit (Nanjing Jiancheng Bioengineering Institute) and AchE kit (Nanjing Jiancheng Bioengineering Institute), respectively.

Statistical analysis. SPSS software (version 18.0; SPSS, Inc.) was used to analyze the data. Differences among multiple groups were statistically analyzed using one-way ANOVA and post hoc comparisons (Bonferroni test). $\mathrm{P}<0.05$ was considered to indicate a statistically significant difference. Each experiment was repeated three times.

\section{Results}

Naringin improved memory and cognition in mice with memory impairment. To investigate the potential of naringin as a therapeutic option for AD, the present study assessed the memory and cognitive abilities of the mice. As presented in Fig. 3A, the NOR index in the model group was significantly decreased when compared with the sham group $(\mathrm{P}<0.01)$. However, compared with the model group, the NOR index in the naringin and KN15112502 groups were increased significantly $(\mathrm{P}<0.01)$. Furthermore, compared with the Naringin group, the NOR index of mice was significantly decreased following the addition of ER inhibitor $(\mathrm{P}<0.05)$. In addition, there was no significant difference in the NOR index between the Naringin group and the KN15112502 group.

To further evaluate the memory and cognition in mice with memory impairment, the present study performed a MWM. The results revealed that, compared with the mice in the sham group, the mice with memory impairment spent more time locating the platform $(\mathrm{P}<0.01)$, and there was no significant difference between naringin-treated mice and control mice. When the ER inhibitor was added, the escape latency of the naringin + ER inhibitor group was significantly increased $(\mathrm{P}<0.01$; Fig. $3 \mathrm{~B})$. On day 5, probe trials were performed to assess the maintenance of spatial memory. Compared with the sham group, mice with memory impairment crossed the platform position less frequently and spent less time on the platform $(\mathrm{P}<0.01)$, and this was significantly reversed with the addition of naringin and KN15112502. However, the ER inhibitor significantly decreased the number of times crossing the platform and the staying time in the naringin + ER inhibitor group of mice ( $\mathrm{P}<0.05$; Fig. 3B).

In Fig. 3C, a significant decrease in the escape latency and a significant increase in the number of mistakes in the model group is observed when compared with the sham group $(\mathrm{P}<0.01)$. However, when Naringin or KN15112502 was added, the escape latency of the mice increased significantly, and the number of mistakes also decreased significantly $(\mathrm{P}<0.01)$. Furthermore, after treatment with the ER inhibitor, the escape 
A
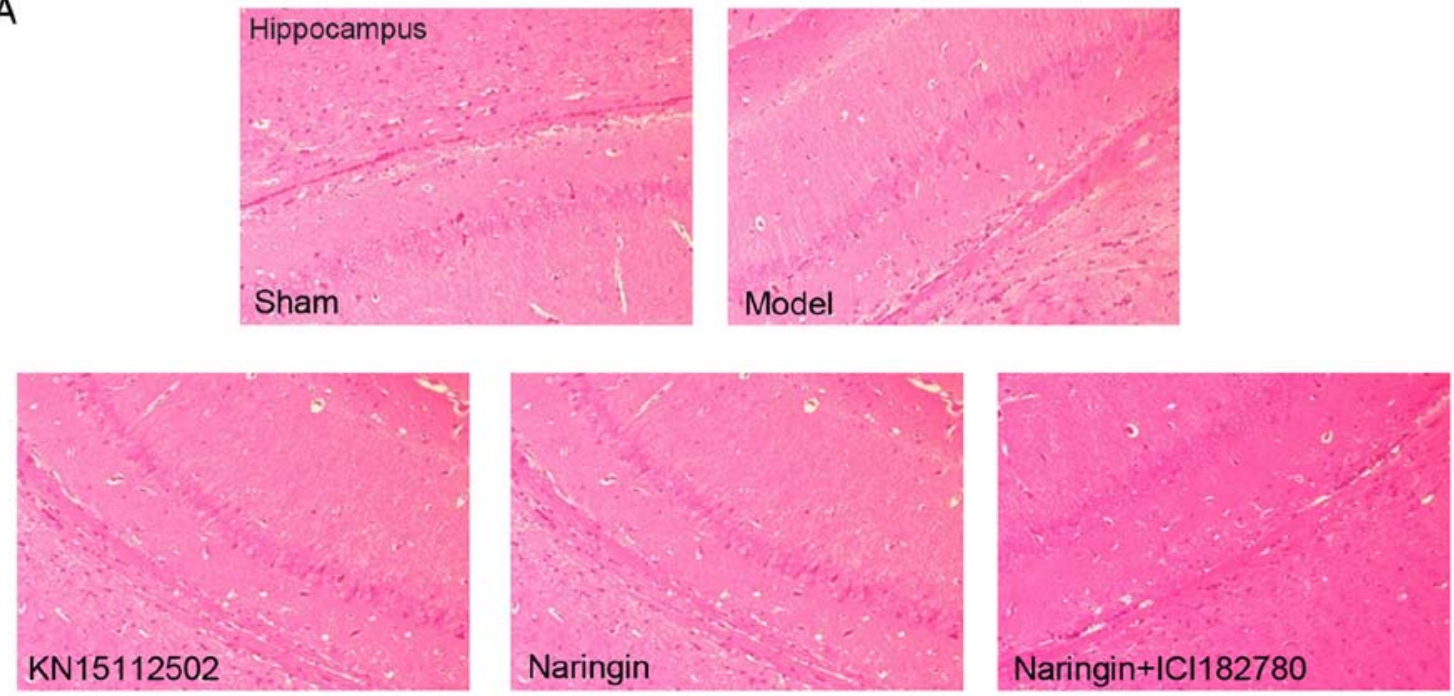

B
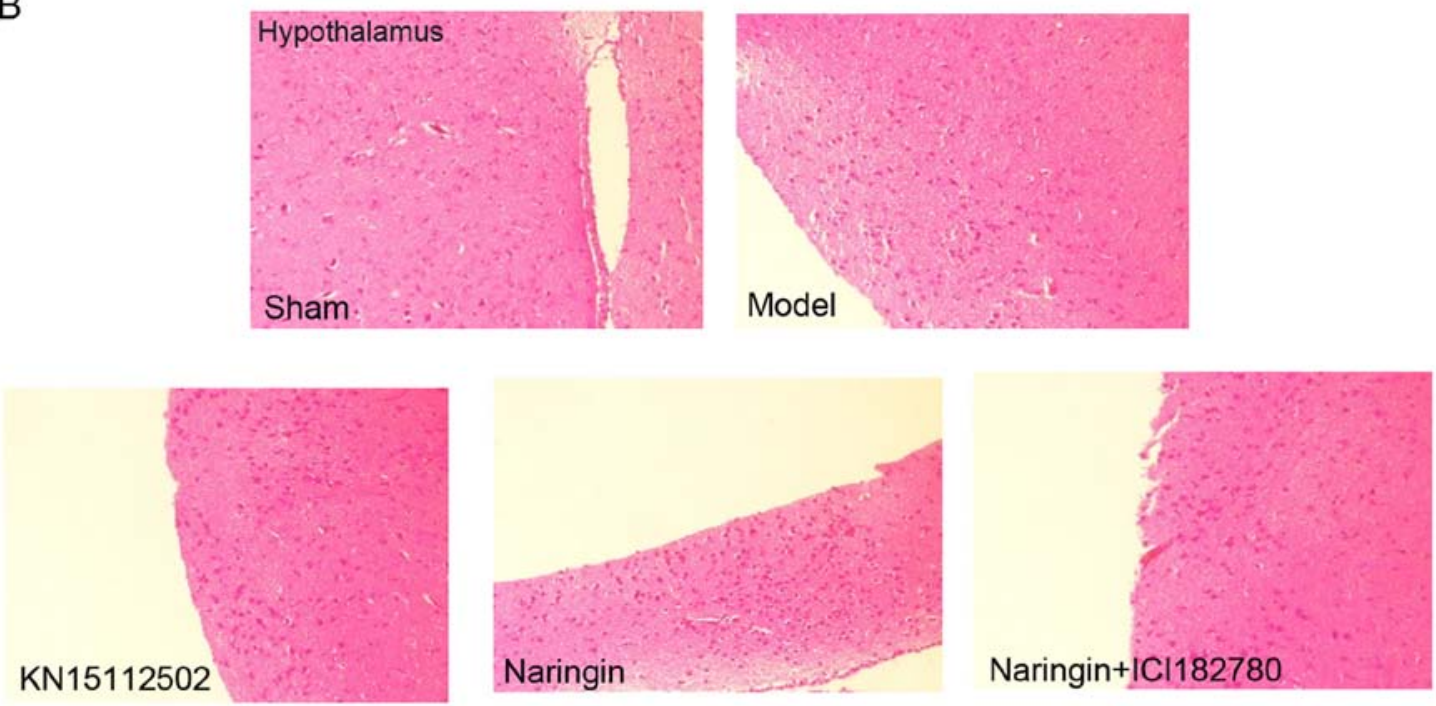

Figure 4. Pathological observation with $\mathrm{H} \& \mathrm{E}$ staining. H\&E staining of the (A) hippocampus and (B) hypothalamus. H\&E, hematoxylin and eosin. Magnification, x200.

latency of the naringin + ER inhibitor group was significantly decreased, and the number of mistakes was significantly increased $(\mathrm{P}<0.05)$.

Pathological observation with $H \& E$ staining. As presented in Fig. 4A and B, the nuclei of the hippocampus and hypothalamus in the sham group were closely and uniformly arranged. The neuron cells were evenly distributed with an intact structure and no nuclear shrinkage was observed. The cells were stained uniformly, with clear and obvious nuclear membranes and nucleoli, and abundant cytoplasm. In the model group, the nuclei of the hippocampal and hypothalamus were arranged loosely and unevenly. The distribution of neuron cells was disordered, the structure was destroyed, the morphology was changed and the number of neuron cells was significantly decreased. In addition, the nuclei were shrunk and the intercellular space was abnormally enlarged.

In the naringin and KN15112502 groups, the nuclei in the hippocampus and hypothalamus of the mice were evenly and tightly arranged. The number of neurons was high, the distribution was relatively uniform and compact, the structure was complete, and there was no obvious nuclear pyknosis. The cells were stained more evenly, and the nuclear membrane and nucleolus were obvious and clear. In the naringin + ER inhibitor group, the arrangement of nuclei in the hippocampus and hypothalamus of the mice was loose and uneven. The structure of neurons was incomplete, the morphology changed, the number of neurons was decreased significantly, and the phenomenon of nuclear pyknosis was common (Fig. 4A and B).

Microstructure observation with TEM. In the sham group, the endoplasmic reticulum and Golgi bodies were widely distributed in the cytoplasm of neurons in the hippocampus, with intact mitochondrial structures and obvious mitochondrial cristae. The nuclear membrane was clear and distinct, the nucleus was normal in size and the chromatin was evenly distributed with a shape of fine sand. The neuropil area was rich in synapses and vesicles with normal structure. There were no lipofuscin particles, and the number of free ribosomes was large. In the model group, the structures of neuron 

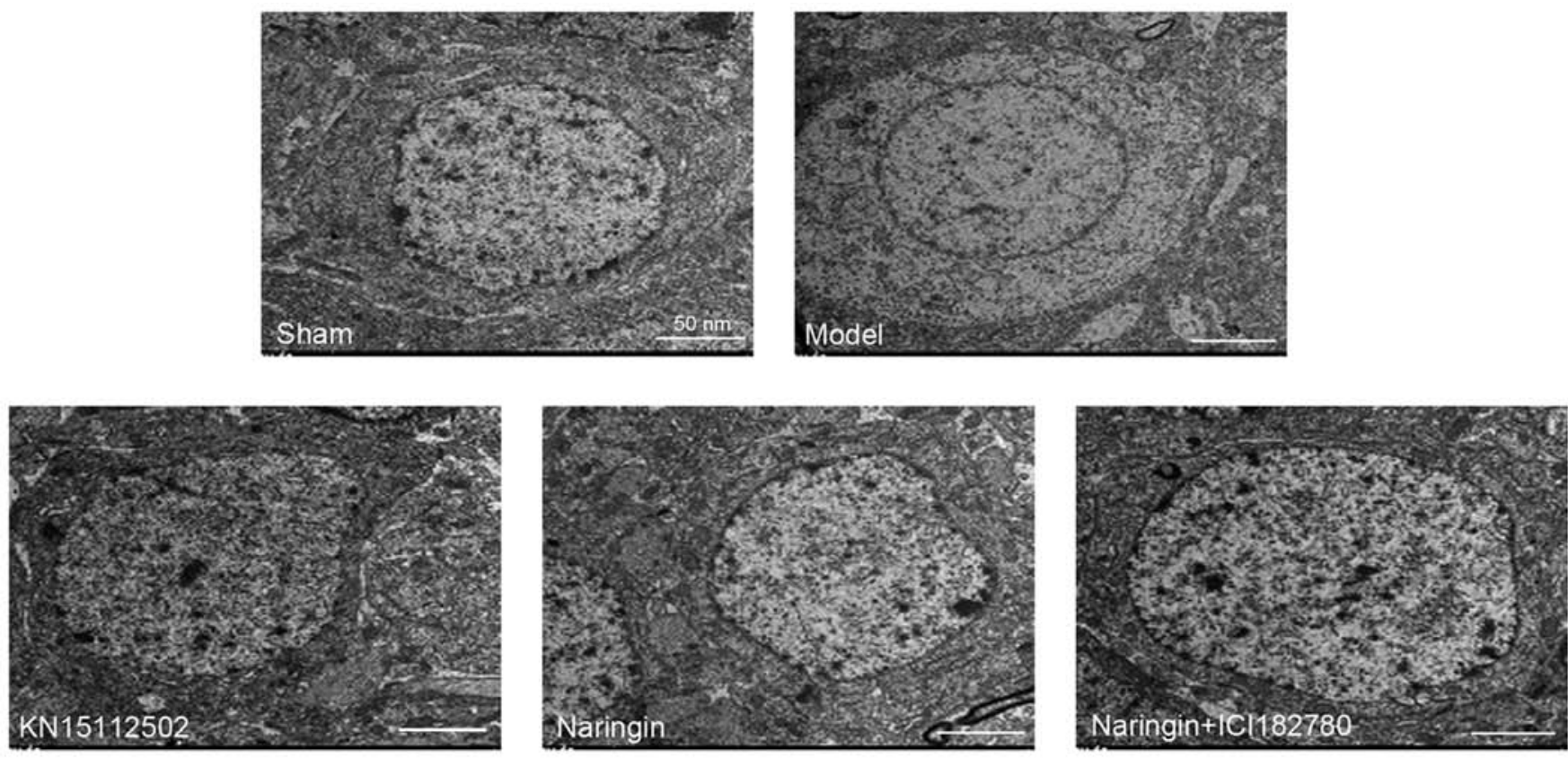

Figure 5. Microstructure observation of hippocampus with TEM. Scale bar, $50 \mathrm{~nm}$. TEM, transmission electron microscopy.

endoplasmic reticulum, mitochondrial cristae and Golgi bodies in the hippocampus of mice were changed, and threshing and swelling occurred. The synapse structure was destroyed and the number was decreased. The lipofuscin particles are generated in large quantities, chromatin is gathered at the edge of the cell. The nucleus of the neuron was significantly contracted and the nuclear membrane was thickened (Fig. 5).

In the naringin and KN15112502 groups, the nuclear membrane and nucleoli of neurons were clearly visible in the hippocampus of mice, and the nucleoli were normal in size. The number of organelles, synapses and vesicles increased, and the structure of mitochondria did not change significantly. In addition, there were fewer lipofuscin particles. In the naringin + ER inhibitor group, the number of lipofuscin particles in the hippocampus increased, the nucleus of the neuron contracted, the nuclear membrane thickened, and chromatin gathered at the edge of the cell. The number of synapses and vesicles decreased, the mitochondrial structure was destroyed, and the endoplasmic reticulum was shelled and expanded (Fig. 5).

Naringin upregulates the expression of ER $\beta$ and ER $\alpha$. To investigate whether the neuroprotective effect of naringin was ER-dependent, immunohistochemical staining was performed in the present study. As presented in Fig. 6A and B, compared with the sham group, the expression levels of ER $\beta$ in the hippocampus and the $\mathrm{ER} \alpha$ in the hypothalamus were significantly decreased. However, following naringin or KN15112502 treatment, all protein expression levels were significantly increased. More notably, when ER inhibitor was added, the expression of the aforementioned proteins was significantly downregulated. In addition, there were no significant differences in the expression of ER $\beta$ in the hippocampus or the $\mathrm{ER} \alpha$ in the hypothalamus between the naringin group and the KN15112502 group. Accordingly, the mean density of ER $\beta$ and ER $\alpha$ showed a consistent trend (Fig. 6A and B).
Naringin exerts neuroprotective effects by affecting $A \beta$ metabolism. To determine whether the neuroprotective effects of naringin affected the metabolic pathways of $A \beta$, the protein expression levels of A $\beta$, APP and BACE1 were detected. As presented in Fig. 7A, it was observed that the expression of $\mathrm{A} \beta$, APP and BACE1 proteins were evidently increased in the hippocampus of model mice, while naringin or KN15112502 significantly inhibited this elevation $(\mathrm{P}<0.01)$. Further, after the addition of ER inhibitor, A $\beta, A P P$ and BACE1 proteins in the hippocampus of mice in the naringin + ER inhibitor group were significantly increased compared with those in the naringin group $(\mathrm{P}<0.05)$.

Naringin exerts neuroprotective effects by inhibiting the hyperphosphorylation of Tau. To assess whether the neuroprotective effect of naringin was involved in the phosphorylation of Tau, the protein expression levels of p-Tau and CDK5 were detected. Compared with the sham group, the expression levels of p-Tau and CDK5 proteins in the hippocampus of the model group mice were significantly increased. Conversely, when Naringin or KN15112502 was added, the expression of both proteins was decreased when compared with the model group $(\mathrm{P}<0.01)$. Furthermore, the addition of ER inhibitor slowed down the inhibitory effect of naringin on $\mathrm{p}$-Tau and CDK5 $(\mathrm{P}<0.05)$. In addition, there were no significant differences in $\mathrm{p}$-Tau and CDK5 protein expression in the hippocampus between the naringin group and the KN15112502 group (Fig. 7B).

Naringin exerts neuroprotective effects by regulating the glutamate receptor system. To assess whether the neuroprotective effects of naringin affected the glutamate receptor system, the protein expression levels of NMDAR1, GluR2 and CAMKII were detected. As depicted in Fig. 8A, hydrocortisone increased the expression of CAMKII protein and decreased the expression of NMDAR1 and GluR2 proteins $(\mathrm{P}<0.01)$. Furthermore, treatment with naringin or KN15112502 
A
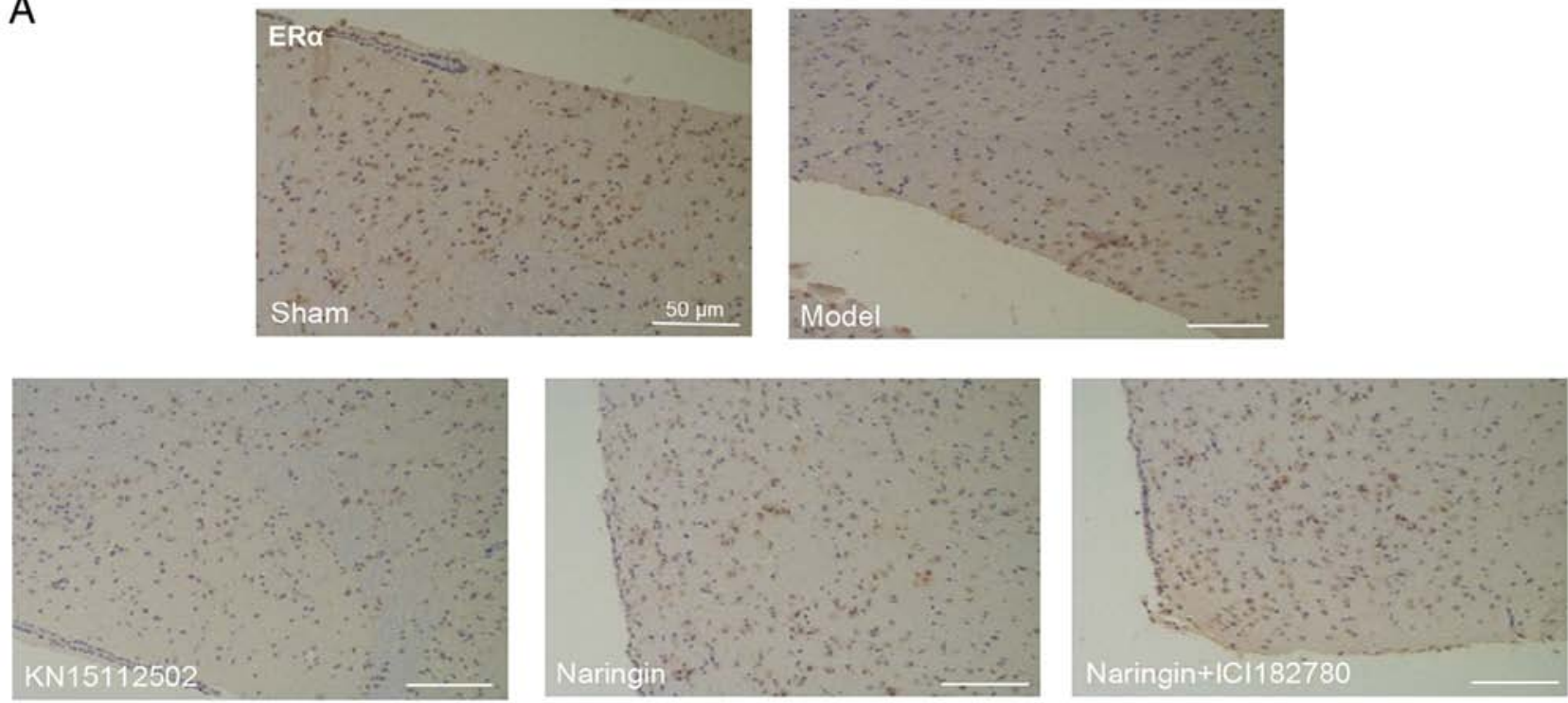

B
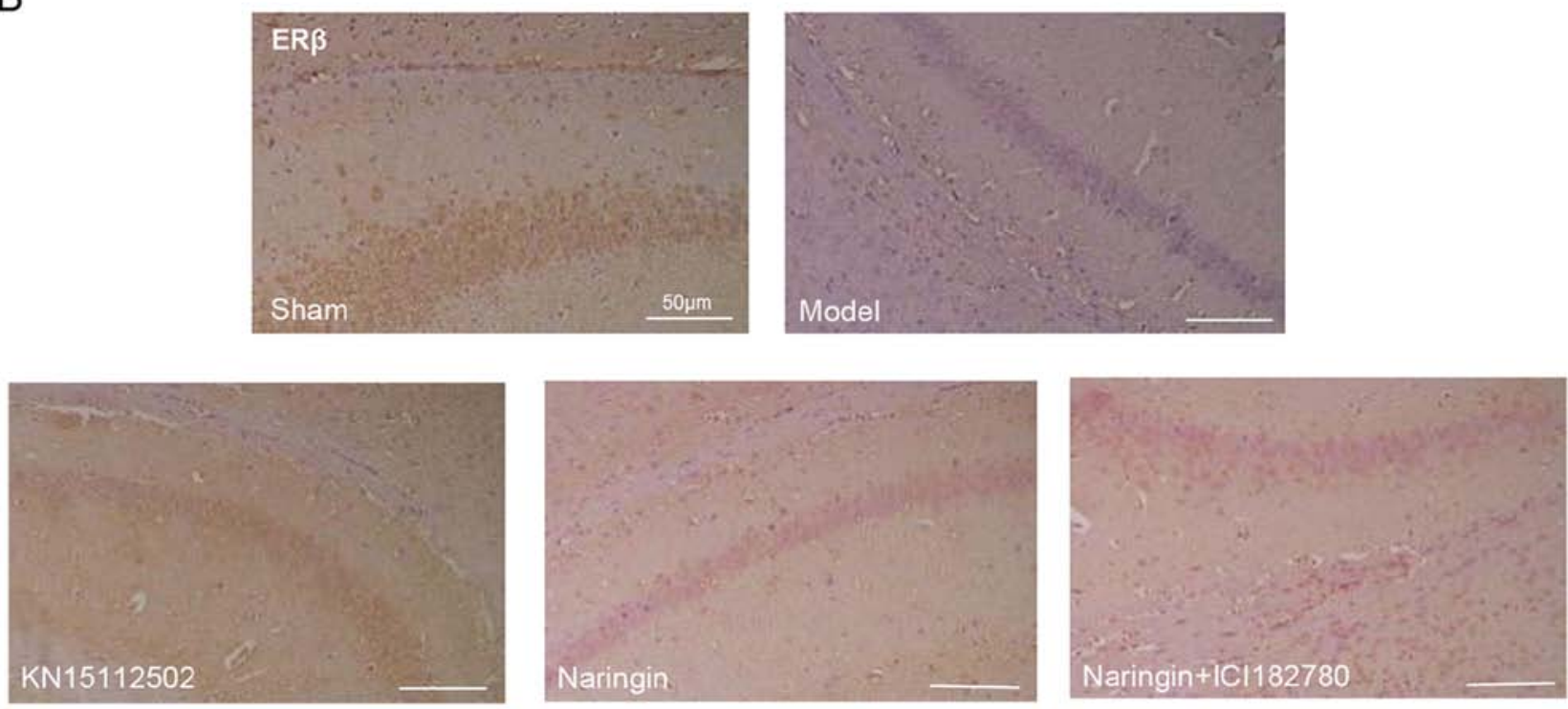

Figure 6. Naringin upregulates the expression of ER $\alpha$ and ER $\beta$. (A) ER $\alpha$ protein level and (B) ER $\beta$ protein level in each group was detected by immunohistochemistry. Scale bar, $50 \mu \mathrm{m}$. ER, estrogen receptor.

reversed the expression of the aforementioned proteins when compared with the model group. Compared with the drug-only group, the addition of ER inhibitors significantly increased the expression of CAMKII protein in the hippocampus. On the contrary, the expression of NMDAR1 and GluR2 proteins were significantly decreased $(\mathrm{P}<0.05)$.

Naringin exerts neuroprotective effects by inhibiting apoptosis. In order to assess whether the neuroprotective effect of Naringin affected cell apoptosis, the present study detected apoptosis-associated protein expression (caspase-3, Bad and Bcl-2). As demonstrated by the western blotting data, hydrocortisone treatment increased the expression of cleaved-caspase-3 and Bad protein, and decreased the expression of $\mathrm{Bcl}-2$ protein $(\mathrm{P}<0.01)$. However, the intervention of Naringin or KN15112502 decreased the expression of cleaved-caspase-3 and Bad protein, but increased the expression of $\mathrm{Bcl}-2$ protein.
Furthermore, the addition of ER inhibitor reversed the effect of naringin on the expression of the aforementioned proteins $(\mathrm{P}<0.05$; Fig. 8B).

Naringin exerts neuroprotective effects by regulating the acetylcholinergic system. To assess whether the neuroprotective effects of naringin affect the acetylcholinergic system, the present study detected the Ach content and the ChAT and AchE activity in the hippocampus of each group. In the model group, the Ach content and the ChAT activity in mice were significantly decreased, while AchE activity was significantly increased $(\mathrm{P}<0.01)$. In the naringin or KN15112502 groups, the expression patterns of the aforementioned three proteins were in contrary to that of the model group, that is, the Ach content and ChAT activity were significantly increased, while AchE activity decreased significantly $(\mathrm{P}<0.01)$. Notably, after the addition of ER inhibitor, the Ach content and the ChAT 

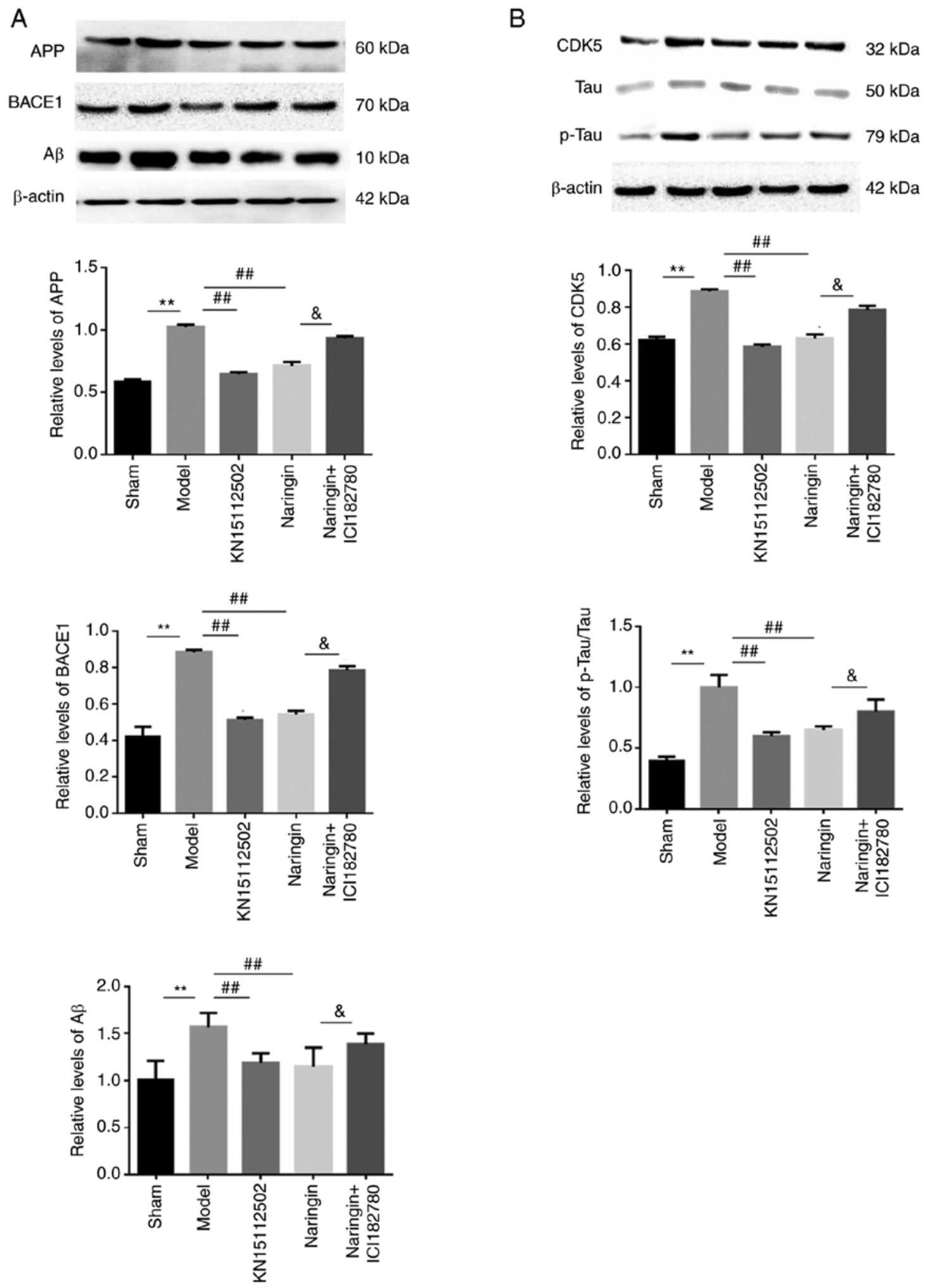

Figure 7. Naringin exerts neuroprotective effects by affecting A $\beta$ metabolism and the hyperphosphorylation of Tau. (A) Protein levels of APP, BACE1 and $\mathrm{A} \beta$; (B) CDK5 and $\mathrm{p}$-Tau. ${ }^{* *} \mathrm{P}<0.01$ vs. sham group; ${ }^{\# \#} \mathrm{P}<0.01$ vs. model group; ${ }^{\circledR} \mathrm{P}<0.05$ vs. naringin group. APP, amyloid protein; BACE1, $\beta$-site APP cleaving enzyme 1; $A \beta$, amyloid $\beta ;$ CDK5, cyclin-dependent kinase 5 .

activity in the in the naringin + ER inhibitor group decreased significantly, while the AchE activity increased significantly ( $<<0.05$; Fig. 9A).

Naringin exerts neuroprotective effects by inhibiting oxidative stress. To assess whether the neuroprotective effect of naringin affected oxidative stress, the content of SOD, MDA and NO were measured in the hippocampus of mice. As presented in Fig. 9B, hydrocortisone increased MDA and NO content and decreased SOD content compared with the Sham group $(\mathrm{P}<0.01)$. In naringin or KN15112502 group, when the corresponding drug intervention was added, the content of MDA 

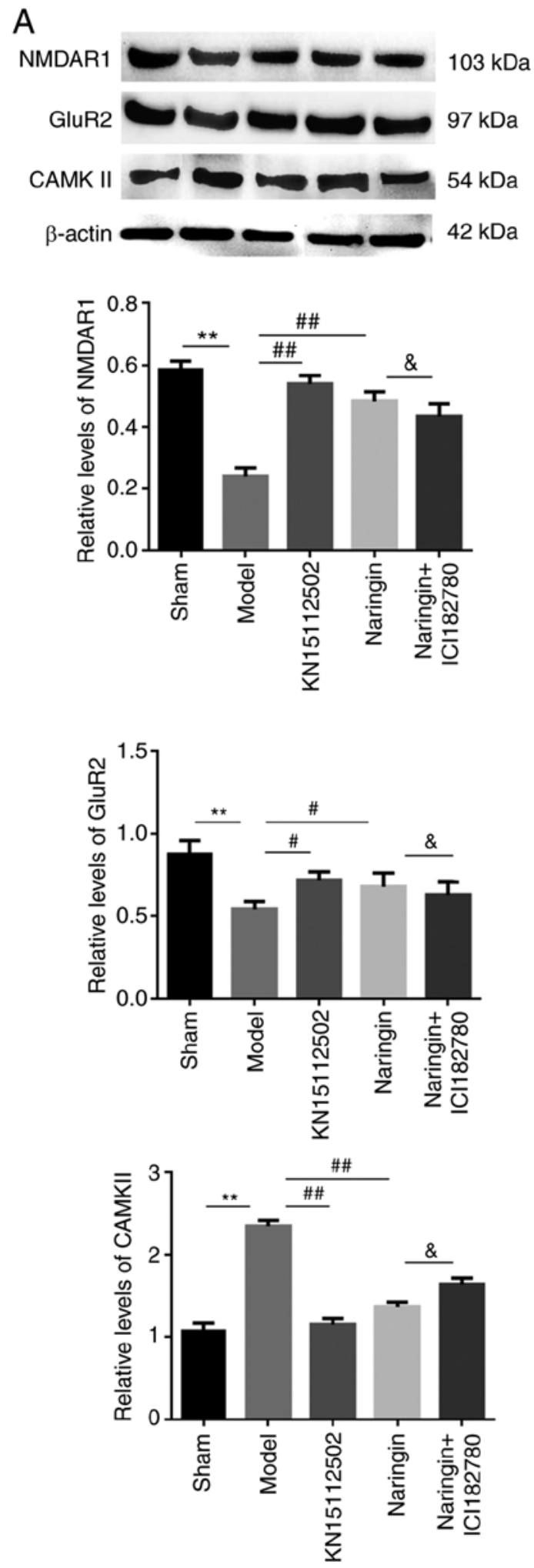

B
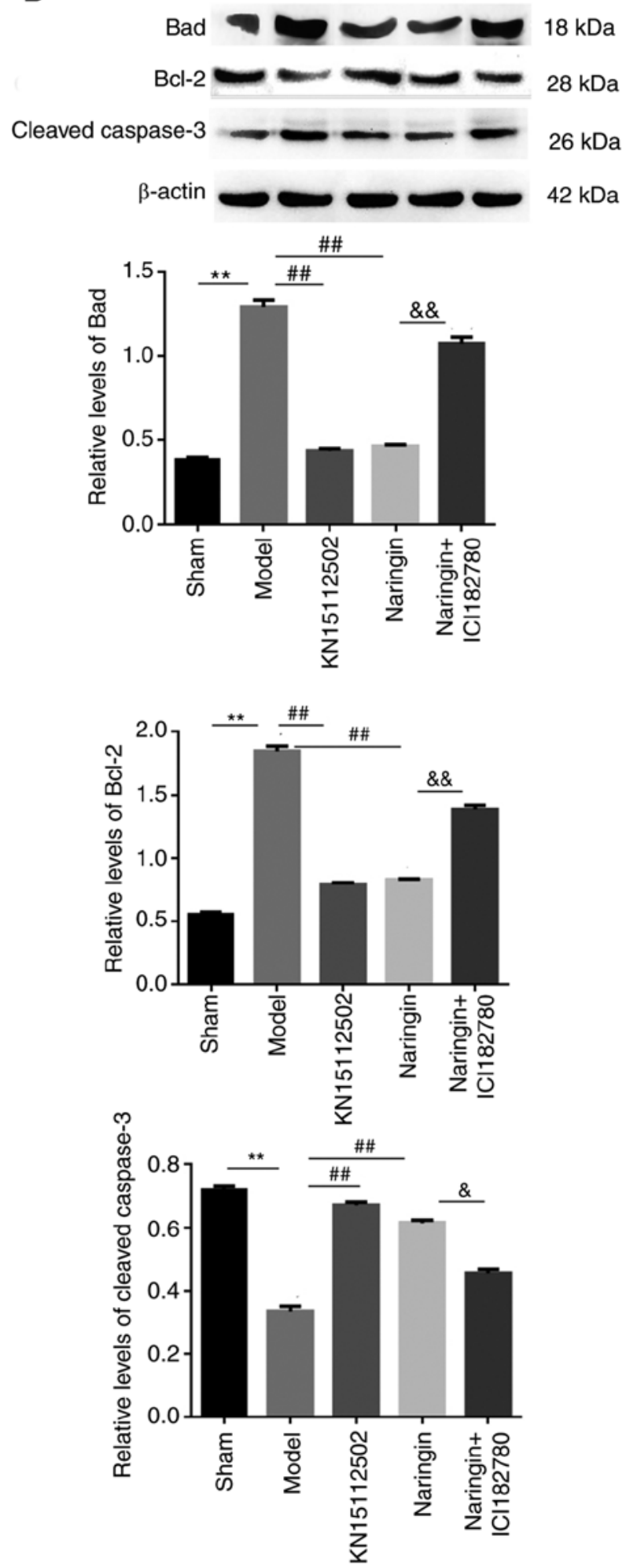

Figure 8. Naringin exerts neuroprotective effects by regulating the glutamate receptor system and apoptosis. (A) Protein levels of NMDAR1, GluR2 and CAMKII. (B) Protein levels of Bad, Bcl-2 and cleaved-caspase- 3 . ${ }^{* *} \mathrm{P}<0.01$ vs. sham group; ${ }^{*} \mathrm{P}<0.05$ and ${ }^{\# \#} \mathrm{P}<0.01$ vs. model group; ${ }^{\&} \mathrm{P}<0.05$, ${ }^{\text {\&\&}} \mathrm{P}<0.01$ vs. naringin group. NMDAR1, glutamate receptor subunit 1; GluR2, glutamate receptor 2; CAMKII, calcium/calmodulin-dependent protein kinase type II.

and NO in the hippocampus was significantly decreased, while the content of SOD significantly increased $(\mathrm{P}<0.01)$. Notably, when ER inhibitor was added, the MDA and NO contents in the naringin + ER inhibitor group were significantly increased, and SOD contents were significantly decreased when compared with naringin $(\mathrm{P}<0.05)$.
Naringin upregulates the expression of ER $\beta$ and downregulates the expression of $P 38 / P-P 38$ in the hippocampus. In order to assess whether the MAPK/P38 signaling pathway was involved in the neuroprotective effect of naringin, the changes in protein expression of P38/p-P38 and ER $\beta$ were detected. As presented in Fig. 10, it was observed that the expression of ER $\beta$ 

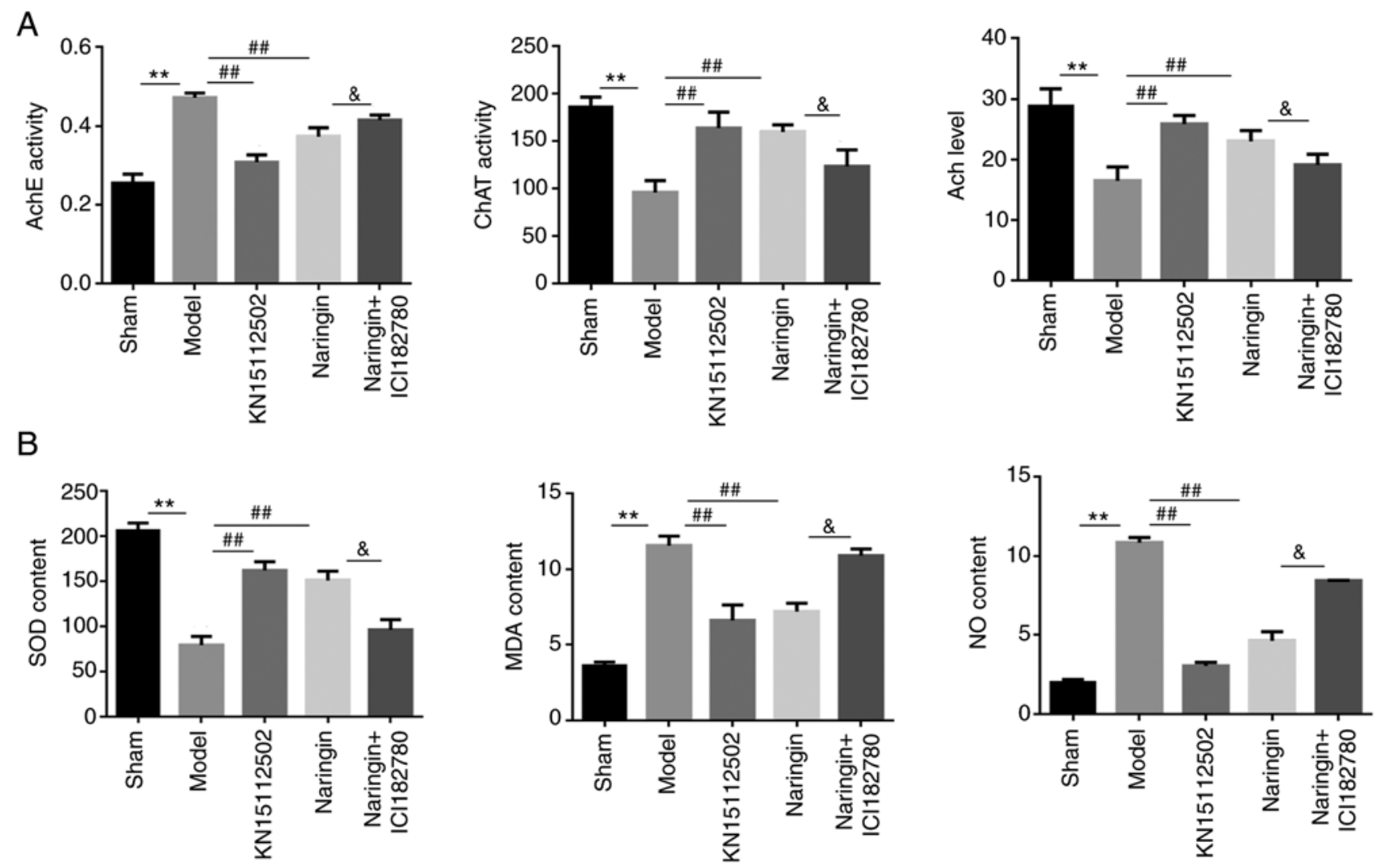

Figure 9. Naringin exerts neuroprotective effects by regulating the acetylcholinergic system and oxidative stress. (A) Naringin significantly increased the Ach content and ChAT activity, but decreasing AchE activity. (B) Naringin significantly decreased the content of MDA and NO in the hippocampus, and the increased the content of SOD. ${ }^{* *} \mathrm{P}<0.01$ vs. sham group; ${ }^{\# \#} \mathrm{P}<0.01$ vs. model group; ${ }^{\circledR} \mathrm{P}<0.05$ vs. naringin group. Ach, acetylcholine; ChAT, choline acetyltransferase; AchE, acetylcholine esterase; MDA, malondialdehyde; NO, nitric oxide; SOD, superoxide dismutase.
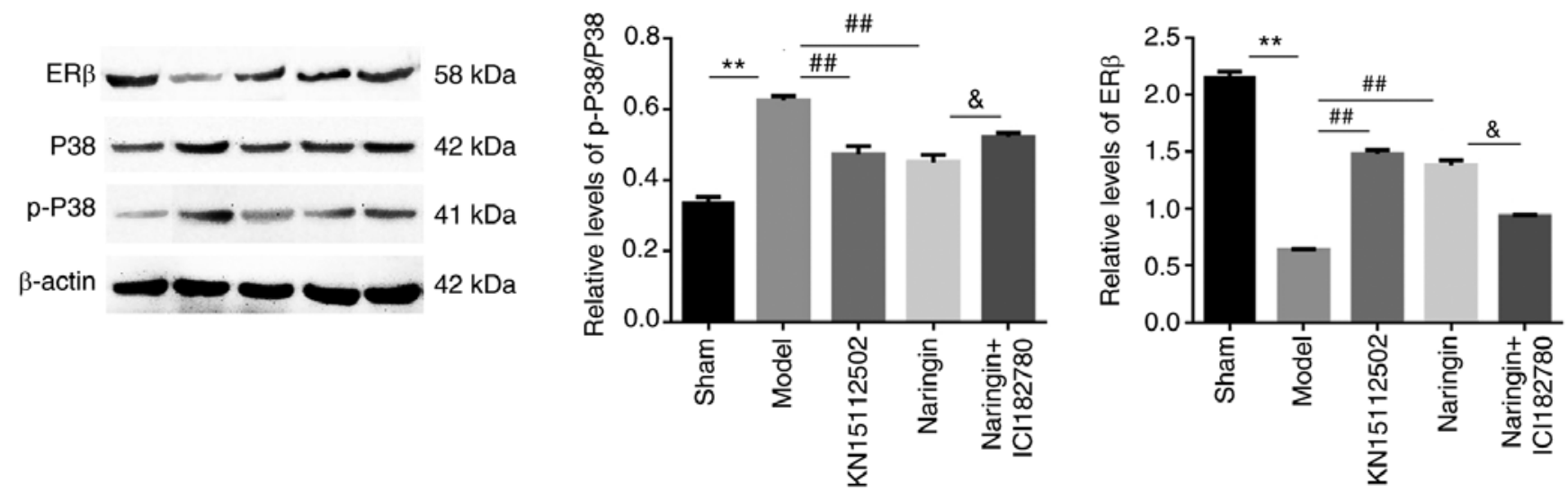

Figure 10. Naringin upregulates the expression of $\mathrm{ER} \beta$ and downregulates the expression of $\mathrm{P} 38 / \mathrm{P}-\mathrm{P} 38$ in the hippocampus. ${ }^{* *} \mathrm{P}<0.01$ vs. sham group; ${ }^{\# \#} \mathrm{P}<0.01$ vs. model group; ${ }^{\circledR} \mathrm{P}<0.05$ vs. naringin group. ER, estrogen receptor; $\mathrm{p}$-, phosphorylated.

protein in the model group was significantly decreased, and the expression of $\mathrm{P} 38 / \mathrm{p}-\mathrm{P} 38$ protein was significantly increased. However, following Naringin or KN15112502 treatment, the expression of P38/P-P38 protein was significantly decreased, while the opposite was observed for $\operatorname{ER} \beta(\mathrm{P}<0.01)$. Notably, when the ER inhibitor was added, the ER inhibitor decreased the effect of naringin on the expression of the aforementioned proteins. In addition, there was no significant difference in $\mathrm{ER} \beta$ and $\mathrm{P} 38 / \mathrm{p}-\mathrm{P} 38$ protein expression between the naringin group and KN15112502 groups.

\section{Discussion}

The obvious clinical manifestation of AD is the decline in learning and memory ability (19). Rodents have an instinctive habit of exploring strange objects, and their learning and cognitive abilities can be reflected by the amount of time spent exploring new and old objects (21). In the present study, NOR results showed that naringin significantly increased the recognition index of the model group mice and improved their memory and learning disabilities. MWM is commonly used to 
measure spatial memory and learning ability (22). The data in the present study indicated that naringin sharply decreased the latency of mice in the model group, and significantly increased the number of times the mice crossed the platform, as well as the residence time in the target quadrant, indicating that naringin could improve their spatial learning and memory ability. The step-down test is designed by using the animals' habits of being active, exploring space, seeking advantages and avoiding disadvantages, and is usually used to test learning and memory abilities (23). When the mice received multiple electric shocks, they will have a memory of this and avoid jumping in again. In the present study, the frequency of receiving electric shock of mice was significantly decreased, and the number of jumping mistakes was also decreased in the naringin group, indicating that naringin could enhance the memory ability of mice. Collectively, behavioral studies indicated that naringin evidently improved the learning and memory disorders of mice with memory impairment, and played a neuroprotective effect.

APP is catalyzed by $\alpha, \beta$ and $\gamma$-type starch secretases, and its products can be divided into soluble amyloid protein (sAPP) and insoluble A $\beta$. $\beta$-site APP cleaving enzyme 1 (BACE1) can catalyze the hydrolysis of APP, which in turn leads to the increase in $A \beta$ production (24). Excessive deposition of $A \beta$ is toxic to nerve cells and can cause nerve cell damage (25). Previously it has been reported that glycyrrhizin decreased the production of $A \beta$, weakened the toxicity to nerve cells and significantly improved memory and cognitive performance in ovariectomized AD model mice (26). The results of the present study demonstrated that naringin inhibited the expression of BACE1, decreased the content of APP and the production of $A \beta$, which had a neuroprotective effect on model mice. Tau protein is a phosphorous microtubule protein, which can stabilize microtubule structure (27). However, its abnormal modification can cause the Tau protein to lose the compositional function of tubulin and trigger the disintegration of microtubules, which affects the normal transport function of neuronal cells and nerve endings (6). Besides, hyperphosphorylated Tau protein has a double-helical structural change, which promotes the formation of NFTs and induces AD. Cyclin-dependent kinase 5 (CDK5) is a major regulatory enzyme for Tau phosphorylation, which can affect the phosphorylation of Tau (28). The inhibition of CDK5 can decrease the production of hyperphosphorylated Tau and thus decrease the damage to nerve cells. For instance, curcumins are suggested to have therapeutic potential for AD by inhibiting Tau phosphorylation (29). In the present study, it was demonstrated that naringin decreased the expression levels of CDK-5 and $\mathrm{p}$-Tau, indicating that naringin played neuroprotective effect by inhibiting the hyperphosphorylation of Tau.

Glutamate (Glu) is an excitatory neurotransmitter that plays a variety of functions by binding to receptors and is an important participant in cognitive and memory functions (30). NMDAR1 and GluR2 are two important receptors in the glutamate system. Excessive Glu activates NMDA excessively, causing continuous large influx of $\mathrm{Ca}^{2+}$, leading to cell damage, and CaMKII is activated and phosphorylated, which intensifies NMDA-mediated $\mathrm{Ca}^{2+}$ influx, causing more serious damage to nerve cells $(31,32)$. In the present study, it was demonstrated that naringin intervention increased the expression of NMDAR1 and GluR2 and inhibited the expression of CaMKII, suggesting that naringin can exert neuroprotective effects by affecting the glutamate receptor system. Neuron loss is an obvious pathological feature of AD, while neuron apoptosis is the main cause of neuron loss (33). In previous molecular research on neuronal cell apoptosis, Bad has been shown to be a pro-apoptotic protein, and $\mathrm{Bcl}-2$ is an anti-apoptotic protein (34). In addition, caspase-3 is the major executor of apoptosis (35). Gu et al (36) showed that FC101 downregulates the expression of Bcl-2, increased the expression of Bad and cleaved caspase-3. In the present study, it was revealed that Naringin inhibited cleaved caspase- 3 and Bad, increased the Bcl- 2 expression, and thereby decreased the apoptosis of cells and played a neuroprotective role, which is consistent with previous reports.

Currently, a previous study has shown that the central cholinergic system in patients with AD is obviously damaged and defective, and is consistent with the clinical symptoms of these patients (7). Ach can regulate the plasticity of synapses in nerve endings for memory and learning (7). ChaT is a key enzyme synthesized by Ach (37), while the main role of AchE is to degrade Ach. In patients with AD, the content of AchE was significantly increased, and the level of ChaT was significantly decreased, resulting in dysfunctions in the synthesis, release and degradation of Ach, and ultimately resulting in a significant decline in brain learning and memory functions (38). In the present study, naringin markedly increased the activity of ChAT in the hippocampus, decreased the activity of AchE, increased the content of Ach and increased the activity and function of cholinergic neurons, thereby exerting neuroprotective effects. Oxidative stress can lead to peroxidation effects on nerve cells, resulting in their damage (39). MDA and excessive NO produced by lipid peroxidation are neurotoxic, and their content can reflect the degree of damage to nerve cells. SOD has a strong antioxidant ability, which can effectively remove excess superoxide anions and decrease the oxidation of cells to achieve the protection of cells (40). Wang et al (41) revealed that Scutellarin can decrease MDA content, enhance SOD activity and decrease cell damage caused by oxidative stress. Consistently, in the present study, Naringin intervention increased the content of SOD and decreased the production of MDA and NO in the hippocampus of mice, indicating that naringin could decrease its toxicity to nerve cells and play a neuroprotective role by inhibiting oxidative stress.

Phytoestrogen-derived plants have similar effects to estrogen and can bind with ER to regulate the gene transcription process of certain substances in neurons so as to control their expression. In addition, it can also mediate multiple signaling pathways to protect nerve cells and improve learning and memory capabilities (42). MAPK is a silk/threonine protein kinase that exerts a series of physiological effects by binding to membrane ERs (43). P38 is one of the main proteins in the MAPK family, and p38 MAPK is the main way for MAPK to regulate the physiological response of cells. When p38 MAPK is stimulated, it forms a stress MAPK signaling pathway, accelerates cell apoptosis and promotes inflammation (44). In the present study, it was demonstrated that naringin significantly increased the protein expression of $\operatorname{ER} \beta$ and ER $\alpha$. However, following the addition of ER inhibitor, the results of the naringin+ER inhibitor group in the 
aforementioned tests were significantly different from those of the naringin group, but almost the same as the results of the model group, suggesting that naringin can play a neuroprotective role in memory-impaired mice through the ER pathway. In addition, it was also revealed that naringin could decrease the $\mathrm{p}-\mathrm{P} 38 / \mathrm{P} 38$ content, indicating that naringin may activate the P38 MAPK pathway after binding with ER and plays a neuroprotective role. However, this mechanism needs to be verified by further experimental studies.

The study concluded that naringin may interact with ERs in the hippocampus of mice to mediate $A \beta$ metabolism, Tau protein hyperphosphorylation, acetylcholinergic system, glutamate receptor system, oxidative stress and cell apoptosis, thereby playing neuroprotective effects. Furthermore, naringin can also affect the expression of p-P38/P38. However, there are some limitations in the present study. Firstly, the direct interaction between naringin and ERs to regulate metabolic pathways associated with AD was not demonstrated; therefore, future studies will prove through further experiments, such as by co-immunoprecipitation studies. Secondly, it was found that Naringin affected the expression of p-P38/P38, but whether it plays a role through the P38 MAPK pathway requires further verification.

\section{Acknowledgements}

Not applicable.

\section{Funding}

This study was supported by National Natural Science Foundation of China (grant no. 81673581), Heilongjiang University of Chinese Medicine Excellent Innovation Talents (grant no. 2018RCD19), Jiamusi University Provincial Universities Fundamental Research Business Expenses Research Project (grant no. 2019-KYYWF-1349), Heilongjiang Postdoctoral Fund (grant no. LBH-Z16252) and Research and development and cultivation projects of scientific and technological achievements of universities in Heilongjiang Province (grant no. TSTAU-C2018020).

\section{Availability of data and materials}

The datasets used and/or analyzed during the current study are available from the corresponding author on reasonable request.

\section{Authors' contributions}

JW and NZ conceived and designed the study. XM, MF and SW provided the materials, and samples and analyzed the data. WC and JW were involved in the acquisition of data. JW and NZ evaluated the authenticity of all the raw data and confirmed its legitimacy. All authors read and approved the final manuscript.

\section{Ethics approval and consent to participate}

This study was approved by the Ethics Committee of Clinical Medical College of Jiamusi University. All procedures are in strict accordance with the recommendations in the Guide for the Care and Use of Laboratory Animals of the National Institutes of Health.

\section{Patient consent for publication}

Not applicable.

\section{Competing interests}

The authors declare that they have no competing interests.

\section{References}

1. Sachdeva AK, Kuhad A and Chopra K: Naringin ameliorates memory deficits in experimental paradigm of Alzheimer's disease by attenuating mitochondrial dysfunction. Pharmacol Biochem Behav 127: 101-110, 2014.

2. Ballatore C, Lee VM and Trojanowski JQ: Tau-mediated neurodegeneration in Alzheimer's disease and related disorders. Nat Rev Neurosci 8: 663-672, 2007.

3. Auld DS, Kornecook TJ, Bastianetto S and Quirion R: Alzheimer's disease and the basal forebrain cholinergic system: Relations to beta-amyloid peptides, cognition, and treatment strategies. Prog Neurobiol 68: 209-245, 2002.

4. Honjo H, Iwasa K, Kawata M, Fushiki S, Hosoda T, Tatsumi H, Oida N, Mihara M, Hirasugi Y, Yamamoto H, et al: Progestins and estrogens and Alzheimer's disease. J Steroid Biochem Mol Biol 93: 305-308, 2005.

5. Gao Y, Li C, Yin J, Shen J, Wang H, Wu Y and Jin H: Fucoidan, a sulfated polysaccharide from brown algae, improves cognitive impairment induced by infusion of $A \beta$ peptide in rats. Environ Toxicol Pharmacol 33: 304-311, 2012.

6. Hampel H, Blennow K, Shaw LM, Hoessler YC, Zetterberg H and Trojanowski JQ: Total and phosphorylated tau protein as biological markers of Alzheimer's disease. Exp Gerontol 45: 30-40, 2010.

7. Ferreira-Vieira TH, Guimaraes IM, Silva FR and Ribeiro FM: Alzheimer's disease: Targeting the cholinergic system. Curr Neuropharmacol 14: 101-115, 2016.

8. Medina M: Recent developments in tau-based therapeutics for neurodegenerative diseases. Recent Pat CNS Drug Discov 6: 20-30, 2011.

9. He LY, He XH, Pang GF, Liang QH, Yang Z and Hu CY: The pathogenesis and treatment of Alzheimer's disease. Chin Geriatric Care Med 15: 12-14, 2017 (In Chinese).

10. Chen L and DiWu YC: Research progress on the relationship between hippocampal nerve cell senescence and neurogenesis and Alzheimer's disease. Hebei J Tradit Chin Med 39: 1583-1587, 2017 (In Chinese)

11. Guzior N, Wieckowska A, Panek D and Malawska B: Recent development of multifunctional agents as potential drug candidates for the treatment of Alzheimer's disease. Curr Med Chem 22: 373-404, 2015.

12. Xu ZL, Xu MY, Wang HT, Xu QX, Liu MY, Jia CP, Geng F and Zhang N: Pharmacokinetics of eight flavonoids in rats assayed by UPLC-MS/MS after oral administration of Drynariae rhizoma extract. J Anal Methods Chem 2018: 4789196, 2018.

13. Yang Z, Kuboyama T and Tohda C: A Systematic strategy for discovering a therapeutic drug for Alzheimer's disease and its target molecule. Front Pharmacol 8: 340, 2017.

14. Chen R, Qi QL, Wang MT and Li QY: Therapeutic potential of naringin: An overview. Pharm Biol 54: 3203-3210, 2016.

15. Golechha M, Sarangal V, Bhatia J, Chaudhry U, Saluja D and Arya DS: Naringin ameliorates pentylenetetrazol-induced seizures and associated oxidative stress, inflammation, and cognitive impairment in rats: Possible mechanisms of neuroprotection. Epilepsy Behav 41: 98-102, 2014.

16. Golechha M, Chaudhry U, Bhatia J, Saluja D and Arya DS: Naringin protects against kainic acid-induced status epilepticus in rats: Evidence for an antioxidant, anti-inflammatory and neuroprotective intervention. Biol Pharm Bull 34: 360-365, 2011.

17. Kumar P and Kumar A: Protective effect of hesperidin and naringin against 3-nitropropionic acid induced Huntington's like symptoms in rats: Possible role of nitric oxide. Behav Brain Res 206: 38-46, 2010. 
18. Cao W, Feng SJ and Kan MC: Naringin targets NFKB1 to alleviate oxygen-glucose deprivation/reoxygenation-induced injury in PC12 cells via modulating HIF-1 $\alpha / \mathrm{AKT} / \mathrm{mTOR}$-signaling pathway. J Mol Neurosci 71: 101-111, 2021.

19. Wang DM, Yang YJ, Zhang L, Zhang X, Guan FF and Zhang LF: Naringin enhances CaMKII activity and improves long-term memory in a mouse model of Alzheimer's disease. Int J Mol Sci 14: 5576-5586, 2013.

20. Li C, Wang $\mathrm{H}$ and Wang L: Replication of a rat model of renal insufficiency Alzheimer's disease. J Anhui Coll Tradit Chin Med 32: 62-67, 2013 (In Chinese).

21. Mathiasen JR and DiCamillo A: Novel object recognition in the rat: A facile assay for cognitive function. Curr Protoc Pharmacol Chapter 5: Unit 5.59, 2010.

22. Gao Y, Yin H, Zhang Y, Dong Y, Yang F, Wu X and Liu H: Dexmedetomidine protects hippocampal neurons against hypoxia/reoxygenation-induced apoptosis through activation HIF-1 $\alpha /$ p53 signaling. Life Sci 232: 116611, 2019.

23. Bolt D, Giger R, Wirth S and Swanenburg J: Step-down test assessment of postural stability in patients with chronic ankle instability. J Sport Rehabil 27: 2018

24. Kimura A, Hata S and Suzuki T: Alternative selection of $\beta$-site APP-cleaving enzyme 1 (BACE1) cleavage sites in amyloid $\beta$-protein precursor (APP) harboring protective and pathogenic mutations within the $\mathrm{A} \beta$ sequence. J Biol Chem 291: 24041-24053, 2016.

25. Holtzman DM, Morris JC and Goate AM: Alzheimer's disease: The challenge of the second century. Sci Transl Med 3: 77sr1, 2011.

26. Ali MY, Jannat S, Edraki N, Das S, Chang WK, Kim HC, Park SK and Chang MS: Flavanone glycosides inhibit $\beta$-site amyloid precursor protein cleaving enzyme 1 and cholinesterase and reduce $A \beta$ aggregation in the amyloidogenic pathway. Chem Biol Interact 309: 108707, 2019.

27. Lopes S, Lopes A, Pinto V, Guimarães MR, Sardinha VM, Duarte-Silva S, Pinheiro S, Pizarro J, Oliveira JF, Sousa N, et al Absence of Tau triggers age-dependent sciatic nerve morphofunctional deficits and motor impairment. Aging Cell 15: 208-216, 2016

28. Saito T, Oba T, Shimizu S, Asada A, Iijima KM and Ando K Cdk5 increases MARK4 activity and augments pathological tau accumulation and toxicity through tau phosphorylation at Ser262. Hum Mol Genet 28: 3062-3071, 2019.

29. Ma QL, Yang F, Rosario ER, Ubeda OJ, Beech W, Gant DJ, Chen PP, Hudspeth B, Chen C, Zhao Y, et al: Beta-amyloid oligomers induce phosphorylation of tau and inactivation of insulin receptor substrate via c-Jun N-terminal kinase signaling: Suppression by omega-3 fatty acids and curcumin. J Neurosci 29 : 9078-9089, 2009.

30. Fan S, Xian X, Li L, Yao X, Hu Y, Zhang M and Li W: Ceftriaxone improves cognitive function and upregulates GLT-1-related glutamate-glutamine cycle in APP/PS1 mice. J Alzheimers Dis 66: 1731-1743, 2018.

31. Ashpole NM and Hudmon A: Excitotoxic neuroprotection and vulnerability with CaMKII inhibition. Mol Cell Neurosci 46 : 720-730, 2011.

32. Pellegrini-Giampietro DE, Gorter JA, Bennett MV and Zukin RS: The GluR2 (GluR-B) hypothesis: $\mathrm{Ca}(2+)$-permeable AMPA receptors in neurological disorders. Trends Neurosci 20 464-470, 1997
33. Caricasole A, Copani A, Caraci F, Aronica E, Rozemuller AJ, Caruso A, Storto M, Gaviraghi G, Terstappen GC and Nicoletti F: Induction of Dickkopf-1, a negative modulator of the Wnt pathway, is associated with neuronal degeneration in Alzheimer's brain. J Neurosci 24: 6021-6027, 2004.

34. Jarskog LF, Selinger ES, Lieberman JA and Gilmore JH: Apoptotic proteins in the temporal cortex in schizophrenia: High Bax/Bcl-2 ratio without caspase-3 activation. Am J Psychiatry 161: 109-115, 2004.

35. Lok J and Martin LJ: Rapid subcellular redistribution of Bax precedes caspase- 3 and endonuclease activation during excitotoxic neuronal apoptosis in rat brain. J Neurotrauma 19: 815-825, 2002.

36. Gu Y, Chen X, Shang C, Singh K, Barzegar M, Mahdavian E, Salvatore BA, Jiang S and Huang S: Fusarochromanone induces G1 cell cycle arrest and apoptosis in COS7 and HEK293 cells. PLoS One 11: e112641, 2014.

37. Goodenough S, Schäfer M and Behl C: Estrogen-induced cell signalling in a cellular model of Alzheimer's disease. J Steroid Biochem Mol Biol 84: 301-305, 2003.

38. Wang H, Muiznieks LD, Ghosh P, Williams D, Solarski M, Fang A, Ruiz-Riquelme A, Pomès R, Watts JC, Chakrabartty A, et al: Somatostatin binds to the human amyloid $\beta$ peptide and favors the formation of distinct oligomers. Elife 6: e28401, 2017.

39. Torres-Cuevas I, Parra-Llorca A, Sánchez-Illana A, Nuñez-Ramiro A, Kuligowski J, Cháfer-Pericás C, Cernada M, Escobar $\mathrm{J}$ and Vento M: Oxygen and oxidative stress in the perinatal period. Redox Biol 12: 674-681, 2017.

40. Amin MM, Rafiei N, Poursafa P, Ebrahimpour K, Mozafarian N, Shoshtari-Yeganeh B, Hashemi M and Kelishadi R: Association of benzene exposure with insulin resistance, SOD, and MDA as markers of oxidative stress in children and adolescents. Environ Sci Pollut Res Int 25: 34046-34052, 2018.

41. Wang $\mathrm{Z}$, Yu J, Wu J, Qi F, Wang $\mathrm{H}$, Wang $\mathrm{Z}$ and $\mathrm{Xu} \mathrm{Z}$ : Scutellarin protects cardiomyocyte ischemia-reperfusion injury by reducing apoptosis and oxidative stress. Life Sci 157: 200-207, 2016

42. Wang YX, Tian K, He CC, Ma XL, Zhang F, Wang HG, An D, Heng B, Jiang YG and Liu YQ: Genistein inhibits hypoxia, ischemic-induced death, and apoptosis in PC12 cells. Environ Toxicol Pharmacol 50: 227-233, 2017.

43. Xu XF, Liu F, Xin JQ, Fan JW, Wu N, Zhu LJ, Duan LF, Li YY and Zhang $\mathrm{H}$ : Respective roles of the mitogen-activated protein kinase (MAPK) family members in pancreatic stellate cell activation induced by transforming growth factor- $\beta 1$ (TGF- $\beta 1$ ). Biochem Biophys Res Commun 501: 365-373, 2018.

44. Sui X, Kong N, Ye L, Han W, Zhou J, Zhang Q, He C and Pan H: p38 and JNK MAPK pathways control the balance of apoptosis and autophagy in response to chemotherapeutic agents. Cancer Lett 344: 174-179, 2014

This work is licensed under a Creative Commons Attribution-NonCommercial-NoDerivatives 4.0 International (CC BY-NC-ND 4.0) License. 